\title{
Humoral immune response against Campylobacter jejuni lipopolysaccharides in Guillain-Barré and Miller Fisher syndrome
}

\author{
B.C. Jacobs ${ }^{\text {a,b, }}{ }^{\text {, H.Ph. Endtz }}{ }^{\text {c }}$, F.G.A. van der Meché ${ }^{a}$, M.P. Hazenberg ${ }^{\text {b }}$, M.A. de Klerk ${ }^{\text {a }}$, \\ P.A. van Doorn ${ }^{\text {a }}$ \\ ${ }^{a}$ Department of Neurology, Erasmus University, P.O. Box 1738, 3000 DR Rotterdam, The Netherlands \\ ${ }^{\mathrm{b}}$ Department of Immunology, Erasmus University, P.O. Box 1738, 3000 DR Rotterdam, The Netherlands \\ ${ }^{c}$ Department of Medical Microbiology and Infectious Diseases, University Hospital, Rotterdam, The Netherlands
}

Received 7 February 1997; revised 7 May 1997; accepted 8 May 1997

\begin{abstract}
In this study we characterized the IgG antibodies against lipopolysaccharides (LPS) of Campylobacter jejuni in serum from patients with Guillain-Barré syndrome (GBS), Miller Fisher syndrome (MFS), C. jejuni enteritis and normal controls. In patients with GBS and MFS long-lasting titers of IgG1 and IgG3 antibodies against LPS from GBS and MFS associated $C$. jejuni were found. The subclass and course of these antibodies were highly associated with those of antibodies against GM1 and GQ1b in GBS and MFS patients. However, in C. jejuni enteritis and normal controls anti-LPS antibodies were predominantly IgG2. Antibody binding with LPS was reduced after treatment with choleratoxin and sialidases, suggesting that the ganglioside-like epitopes in LPS are immunodominant. These results further indicate that antecedent $C$. jejuni infections determine the specificity and isotype of anti-ganglioside antibodies in GBS and MFS patients. (C) 1997 Elsevier Science B.V.
\end{abstract}

Keywords: Guillain-Barré syndrome; Miller Fisher syndrome; Campylobacter jejuni; Lipopolysaccharides; GM1; GQ1b

\section{Introduction}

The Guillain-Barré syndrome (GBS) is an acute monophasic polyneuropathy leading to a heterogeneous spectrum of motor and sensory deficits (Van der Meché and Van Doorn, 1995). The Miller Fisher syndrome (MFS), characterized by ophthalmoplegia, areflexia and ataxia, is considered to be one of its variants. GBS and MFS may result from a transient immune response against peripheral nerves, triggered by an infection which often preceeds the neurological onset.

Campylobacter jejuni is a frequent cause of antecedent infections in GBS (Rees et al., 1995a), and MFS (Yuki et al., 1994; Jacobs et al., 1995). These infections are associated with the presence of antibodies against gangliosides in patients with GBS (Walsh et al., 1991; Rees et al., 1995b; Jacobs et al., 1996) and MFS (Yuki et al., 1994; Jacobs et al., 1995). Anti-GM1 antibodies are associated with severe

\footnotetext{
* Corresponding author. Tel.: +31-10-4088209; fax: +31-10-4367085.
}

motor involvement in GBS (Jacobs et al., 1995) and anti-GQ1b antibodies with MFS and oculomotor involvement in GBS (Chiba et al., 1993). The high concentration of GM1 in myelin of motor nerves (Ogawa-Goto et al., 1992) and of GQ1b in oculomotor nerves (Chiba et al., 1993) reflects these clinical manifestations. These antibodies may be induced by the infection, since ganglioside-like epitopes are found in lipopolysaccharides (LPS) of $C$. jejuni isolates from patients with GBS (Yuki et al., 1993) and MFS (Salloway et al., 1996). Furthermore, anti-GM1 IgG antibodies from GBS patients cross-react with GBS associated C. jejuni (Oomes et al., 1995), and anti-GQ1b IgG antibodies with MFS associated isolates (Yuki et al., 1994; Jacobs et al., 1995).

Two issues considering the cross-reactivity of anti-LPS antibodies in GBS need to be clarified. Firstly, in approximately half of the GBS patients with $C$. jejuni infections no antibodies against gangliosides are found (Walsh et al., 1991; Rees et al., 1995b; Jacobs et al., 1996). These patients may have LPS induced antibodies which cross-react with other peripheral nerve antigens. So far, antibodies against $C$. jejuni LPS were investigated only in small 
groups of GBS patients with anti-GM1 antibodies, but not in GBS patients without these antibodies.

Secondly, ganglioside-like epitopes are also demonstrated in $C$. jejuni isolates from enteritis patients without GBS or MFS (Aspinall et al., 1993; Yuki et al., 1994; Jacobs et al., 1995). This indicates that, in addition to the fine-specificity, other features of the cross-reactive antibodies determine their possible pathogenicity. The subclass may be important since it determines the effector functions of the antibodies. In general, IgG antibodies against bacterial polysaccharides are predominantly of the $\mathrm{IgG} 2$ subclass (Hammerström and Smith, 1986). Antibodies against gangliosides in GBS and MFS patients, however, are predominantly IgG1 and IgG3 (Willison and Veitch, 1994; Ogino et al., 1995; Yuki et al., 1995). So far, a comparative study on the IgG subclasses of anti-LPS antibodies in patients with GBS, and in $C$. jejuni enteritis without GBS has not been performed.

To further characterize the humoral immune response against $C$. jejuni LPS, we studied the presence, course, subclass distribution and specificity of serum IgG antibodies against $C$. jejuni LPS in a large and heterogeneous group of GBS and MFS patients, compared to patients with $C$. jejuni enteritis and normal controls.

\section{Patients and methods}

\subsection{C. jejuni isolates and lipopolysaccharides}

C. jejuni was isolated from 3 patients with MFS (A, B and C), 3 patients with GBS (D, E and F) and 3 enteritis controls without neurological involvement (1,2 and 3). Patients A-E and 1-3 and their C. jejuni isolates were described previously (Jacobs et al., 1995; Jacobs et al., in press). Patients A, B and C suffered from ophthalmoplegia, ataxia and areflexia without limb weakness, and patients $\mathrm{D}, \mathrm{E}$ and $\mathrm{F}$ fulfilled the diagnostic criteria for GBS (Asbury and Cornblath, 1990). Serum anti-ganglioside antibodies were found in MFS patient A and C (GQ1b, GD1b, GD3), B (GQ1b) and GBS patient D (GM1, GD1b), but not in GBS patient E. Serum from GBS patient $F$ and enteritis controls 1-3 was not available. The $C$. jejuni isolates were serotyped according to the Penner classification system, which is based on the bacterial LPS, as O:4,50 (A), non-typable (B and F), 0:23 (C and 1), O:1 (D), O:24 (E), O:22 (2) and O:41 (3). C. jejuni was grown for $48 \mathrm{~h}$ on blood agar plates in a microaerobic atmosphere, inactivated in $1 \%$ formaldehyde and washed in phosphatebuffered saline solution (PBS) ( $\mathrm{pH}$ 7.4). The LPS fractions from $C$. jejuni were isolated by phenol-water extraction (Westphal and Jann, 1965) and were demonstrated to contain less than $1 \%$ protein.

\subsection{Sera from GBS, MFS and control patients}

Serum samples from 41 GBS patients, 3 MFS patients, 12 C. jejuni enteritis controls (CJC) without neurological involvement, and 12 normal controls (NC) were tested for IgG antibodies against LPS. The patients were subdivided into 6 groups depending on the presence of antibodies against GM1 or GQ1b and antecedent $C$. jejuni infection (Table 1). Recent $C$. jejuni infections were serologically defined as the presence of $\operatorname{IgM}, \operatorname{IgA}$, or high titers of $\operatorname{IgG}$ antibodies against $C$. jejuni in ELISA, as previously described (Jacobs et al., 1996). The CJC had diarrhea and a positive $C$. jejuni serology. The samples from the GBS and MFS patients were obtained within 2 weeks of neurological symptoms and before treatment. All sera were tested for antibodies against the gangliosides GM1, GM3, GD1a, GD1b, GD3, GT1b and GQ1b, by enzyme linked immunoadsorbent assay (ELISA) and thin-layer chromatography overlay, according to methods described previously (Jacobs et al., 1996).

\subsection{Detection of antibodies against lipopolysaccharides}

Serum antibodies against LPS were tested in ELISA, by coating 96-well polystyrene microtiter trays (Immuno Maxisorb, Roskilde) with $1 \mu \mathrm{g}$ of LPS in $50 \mu$ l PBS per well overnight at $37^{\circ} \mathrm{C}$. Unspecific binding sites were blocked for $4 \mathrm{~h}$ with PBS containing $1 \%$ bovine serum

Table 1

Anti-ganglioside antibodies and $C$. jejuni infections in patients tested for antibodies against $C$. jejuni lipopolysaccharides

\begin{tabular}{|c|c|c|c|c|c|c|}
\hline \multirow[t]{2}{*}{ Group } & \multicolumn{2}{|l|}{ Patients } & \multicolumn{2}{|c|}{ IgG antibodies } & \multirow[t]{2}{*}{ C. jejuni infection ${ }^{\mathrm{a}}$} & \multirow[t]{2}{*}{ Including patient } \\
\hline & number & diagnosis & GM1 & GQ1b & & \\
\hline 1 & 12 & GBS & 12 & 0 & $9(75 \%)$ & $\mathrm{D}$ \\
\hline 3 & 12 & GBS & 0 & 0 & $12(100 \%)$ & $\mathrm{E}$ \\
\hline 4 & 12 & GBS & 0 & 0 & 0 & \\
\hline 5 & 12 & CJC & 0 & 0 & $12(100 \%)$ & \\
\hline 6 & 12 & $\mathrm{NC}$ & 0 & 0 & 0 & \\
\hline
\end{tabular}

GBS, Guillain-Barré syndrome; MFS, Miller Fisher syndrome; CJC, C. jejuni enteritis control without neurological involvement; NC, normal control.

${ }^{a}$ Defined as positive C. jejuni serology (Jacobs et al., 1996). 
albumine (BSA) (Sigma, St. Louis, MO). After blocking, the plates were incubated overnight at $4^{\circ} \mathrm{C}$ with serum diluted 1:1000 in PBS-1\% BSA. After washing with PBS, the plates were incubated with peroxidase-conjugated goat antihuman IgG ( $\gamma$-chain specific) (Sigma), diluted 1:2500 in PBS-1\% BSA, for $90 \mathrm{~min}$ at room temperature. After washing with PBS, the plates were developed with $O$ phenyl diamine (Sigma) in citrate buffer ( $\mathrm{pH}$ 5.0) and the optical densities (ODs) were read at $490 \mathrm{~nm}$. All samples were assayed in duplicate. The serum was tested in both LPS-coated and blank wells, allowing the OD values to be calculated after subtraction of the blank well OD from the coated-well OD. Serum samples with ODs of more than 3 SD above the mean value of $12 \mathrm{NC}$ sera were considered to be of high titer, and were further tested to determine the IgG subclasses. These samples were diluted 1:250 in PBS$1 \%$ BSA and tested according to the same protocol. Subclasses were identified by using peroxidase-conjugated monoclonal goat antihuman IgG1 (clone MH161-1), IgG2 (clone HP6014), IgG3 (clone MH163-1) and IgG4 (clone MH164-4) (CLB, Amsterdam) diluted 1:100, 1:200, 1:200 and 1:200 in PBS-1\% BSA, respectively. All serum samples were also tested for $\mathrm{IgG} 1$ and $\mathrm{IgG} 2$ antibodies against Pneumovax (Merck, Sharp and Dohme, Haarlem), a mixture of capsular polysaccharides from 23 different serotypes of Streptococcus pneumoniae, by routine techniques.

\subsection{Sialidase treatment of lipopolysaccharides}

The LPS fractions were incubated with $0.05 \mathrm{U} / \mathrm{ml}$ of sialidase from Clostridium perfringens (CP) (Sigma) or
Arthrobacter ureafaciens (AU) (Sigma) in $50 \mathrm{mM}$ of sodium acetate buffer $(\mathrm{pH} 5.5)$ overnight at $37^{\circ} \mathrm{C}$. After incubation, the LPS were incubated at $80^{\circ} \mathrm{C}$ for $30 \mathrm{~min}$ to inactivate the sialidases. In control studies, the LPS were incubated in the same conditions without sialidases. Antibodies against the desialylated LPS were further tested according to the method described in Section 2.3.

\subsection{Cholera toxin treatment of lipopolysaccharides}

The LPS fractions were coated according to the protocol described in 2.3, and incubated with $25 \mu \mathrm{g} / \mathrm{ml}$ of B subunit of cholera toxin (CT) (Sigma) in PBS-1\% BSA overnight at $4^{\circ} \mathrm{C}$. The plates were emptied before further testing. In control studies, the LPS were incubated in the same conditions without CT. Antibodies against the CT blocked LPS were further tested according to the method described in Section 2.3.

\section{Results}

\subsection{IgG antibodies against LPS}

In the anti-GM1 positive patients (group 1), 9 (75\%) of 12 patients had high IgG activity against LPS of $C$. jejuni isolates from MFS patient A, GBS patients D, E and F, or control 3 (Fig. 1). Six patients had IgG antibodies against all these isolates, 2 only against the 3 GBS associated isolates and 1 only against GBS related isolate F. All these patients with anti-LPS antibodies had a recent $C$. jejuni

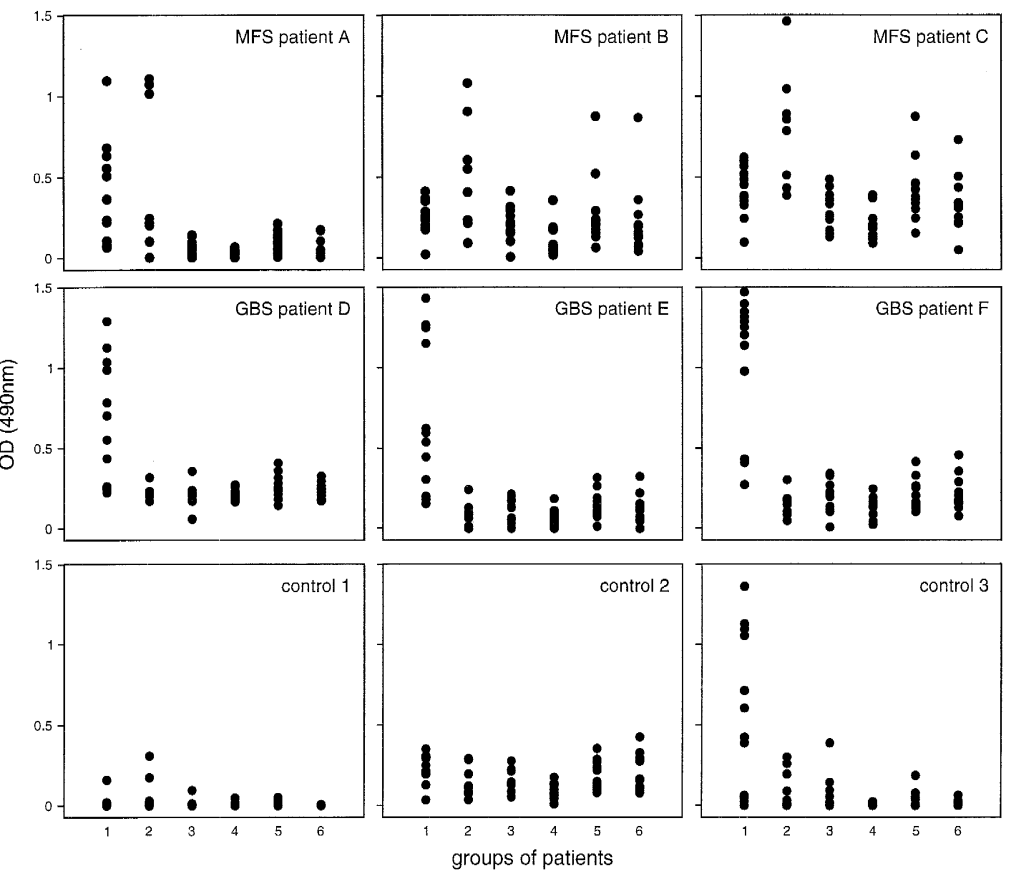

Fig. 1. Serum IgG activity against LPS from C. jejuni isolates from MFS patients (A, B, C), GBS patients (D, E, F), and enteritis controls without neurological involvement $(1,2,3)$. The patients tested for $\operatorname{IgG}$ activity were subdivided into 6 groups according to diagnosis, presence of anti-ganglioside infections and antecedent $C$. jejuni infections (see Table 1). 
infection. The 3 patients without anti-LPS activity had no C. jejuni infection and 2 had lower anti-GM1 IgG titers than $1: 1000$. No evident difference in additional IgG activity against other gangliosides was found in the patients with anti-LPS IgG antibodies compared to those without. However, the 6 patients with $\operatorname{IgG}$ against the $C$. jejuni isolate A all had additional anti-GD1b antibodies (data not shown).

In the anti-GQ1b positive patients (group 2), 6 (75\%) of 8 patients had high IgG activity against LPS of $C$. jejuni isolates from MFS patients A, B or C (Fig. 1). IgG activity against at least 2 of these isolates was found in 5 patients. Four of the patients with anti-LPS antibodies had a recent C. jejuni infection. No difference was found in anti-GQ1b IgG titer or antibodies against other gangliosides between patients with anti-LPS antibodies compared to those without. In the anti-GM1/GQ1b negative GBS patients, high IgG activity against LPS was found only in $1(8 \%)$ of the 12 patients with $C$. jejuni infection (group 3), which was to LPS from control isolate 3, and in none of the 12 patients without this infection (group 4) (Fig. 1). Two (17\%) of the 12 C. jejuni infected controls without GBS or MFS (group 5), and 1 (8\%) of the 12 normal controls (group 6) had high anti-LPS IgG activity. The IgG in these patients reacted with LPS from the MFS associated isolates B and C (Fig. 1).

In GBS patients with high anti-LPS activity follow-up samples obtained at 3 or 6 months were also tested. The anti-LPS IgG activity in these samples was lower than in pretreatment samples, although the activity was still higher than in normal controls. The antibody activity against LPS showed a similar course as the activity against gangliosides in individual patients (Fig. 2).

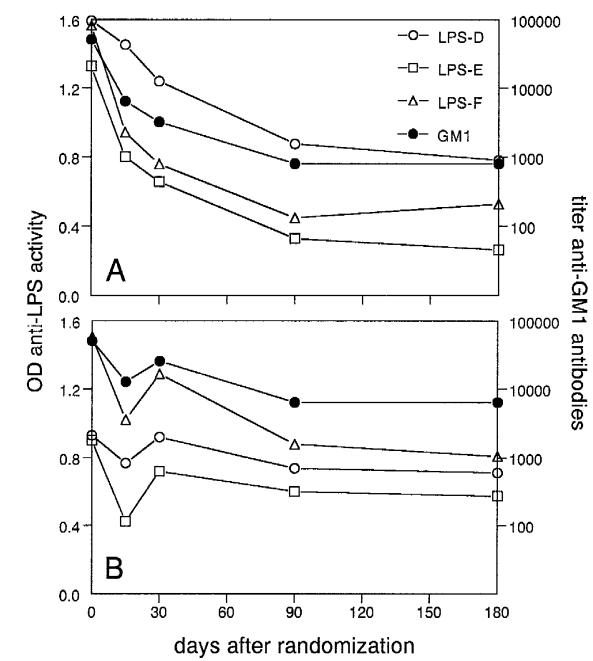

Fig. 2. Follow-up of $\operatorname{IgG}$ antibody activity against LPS of 3 GBS associated C. jejuni isolates (D, E, F) (expressed as extinctions) and of anti-GM1 IgG activity (expressed as titers) in two GBS patients with $C$. jejuni infection, one treated with intravenous immunoglobulins (A), and one with plasma exchange (B).
Table 2

Subclasses of IgG antibodies against GM1, GQ1b and $C$. jejuni LPS in serum from patients with GBS, MFS, and CJC and NC with high titers of anti-LPS antibodies

\begin{tabular}{|c|c|c|c|c|c|c|c|c|c|c|}
\hline \multirow[t]{3}{*}{ Group } & \multirow[t]{3}{*}{ Patient } & \multirow[t]{3}{*}{ GM1 } & \multirow[t]{3}{*}{ GQ1b } & \multicolumn{7}{|c|}{ Lipopolysaccharides a } \\
\hline & & & & \multicolumn{3}{|c|}{ MFS } & \multicolumn{3}{|c|}{ GBS } & \multirow{2}{*}{$\frac{\text { Control }}{3}$} \\
\hline & & & & A & B & $\mathrm{C}$ & $\mathrm{D}$ & E & $\mathrm{F}$ & \\
\hline \multirow[t]{10}{*}{ GBS } & 1 & 1 & - & - & - & - & 1 & 1 & 1,3 & 1 \\
\hline & 2 & 1 & - & 1 & - & - & 1 & 1 & 1 & 1 \\
\hline & 3 & 3,1 & - & 3,1 & - & - & 3,1 & 3,1 & 3,1 & 3,1 \\
\hline & 4 & 1 & - & 1 & - & - & 1 & 1 & 1 & 1 \\
\hline & 5 & 1 & - & 1 & - & - & 1 & 1 & 1 & 1 \\
\hline & 6 & 1 & - & - & - & - & 1 & 1 & 1 & 1 \\
\hline & 7 & 1,3 & - & 1 & - & - & 1 & 1 & 1,3 & 1 \\
\hline & 8 & 1 & - & 1 & - & - & 1 & 1 & 1,3 & 1 \\
\hline & 9 & 1 & - & - & - & - & - & - & 1 & - \\
\hline & 10 & - & - & - & - & - & - & - & - & 1 \\
\hline \multirow[t]{6}{*}{ GBS /MFS } & 11 & - & 3,1 & 3,1 & - & 3,1 & - & - & - & - \\
\hline & 12 & - & 1 & 1 & - & - & - & - & - & - \\
\hline & 13 & - & 3 & - & 3 & 3 & - & - & - & - \\
\hline & 14 & - & 3,1 & 3,1 & 3,1 & 3,1 & - & - & - & - \\
\hline & 15 & - & 3 & - & 1 & 3,1 & - & - & - & - \\
\hline & 16 & - & 3 & - & 3,1 & 3,1 & - & - & - & - \\
\hline \multirow[t]{2}{*}{ CJC } & 17 & - & - & - & 2 & 2 & - & - & - & - \\
\hline & 18 & - & - & - & 2 & 2 & - & - & - & - \\
\hline $\mathrm{NC}$ & 19 & - & - & - & 2,1 & 2 & - & - & - & - \\
\hline
\end{tabular}

GBS, Guillain-Barré syndrome; MFS, Miller Fisher syndrome; CJC, $C$, jejuni enteritis control without neurological involvement; $\mathrm{NC}$, normal control.

${ }^{a}$ LPS from $C$. jejuni isolates from MFS patients (A, B, C), GBS patients (D, E, F) and an enteritis control without neurological involvement (3). Numbers 1 to 4 refer to the presence of subclasses IgG1 to IgG4, respectively, with the first mentioned being the predominant subclass.

Axonal degeneration, as indicated by the presence of denervation potentials, was found in $5(50 \%)$ of 10 patients in group 1, 2 (25\%) of 8 patients in group 2, $2(20 \%)$ of 10 patients in group 3, and 1 (9\%) of 11 patients in group 4. No clear association between the presence of anti-LPS antibodies and axonal degeneration could be demonstrated.

\subsection{Subclasses of IgG antibodies against gangliosides and $L P S$}

The subclass of the IgG antibodies against GM1, GQ1b and LPS were determined in all patients with high $\operatorname{IgG}$ activity against LPS, and are given in Table 2. IgG antibodies against GM1 or GQ1b were all of the IgG1 or IgG3 subclasses. In most patients the predominant isotype of anti-GM1 antibodies was IgG1, and of anti-GQ1b antibodies was IgG3. In GBS and MFS patients the IgG antibodies against LPS were also of the IgG1 or IgG3 subclasses and generally corresponded with the isotype of the anti-ganglioside antibodies in individual patients (Table 2). However, in serum from CJC and NC, antibodies against LPS from $C$. jejuni isolates $\mathrm{B}$ and $\mathrm{C}$ were predominantly $\mathrm{IgG} 2$. Control studies demonstrated that IgG2 antibodies against 


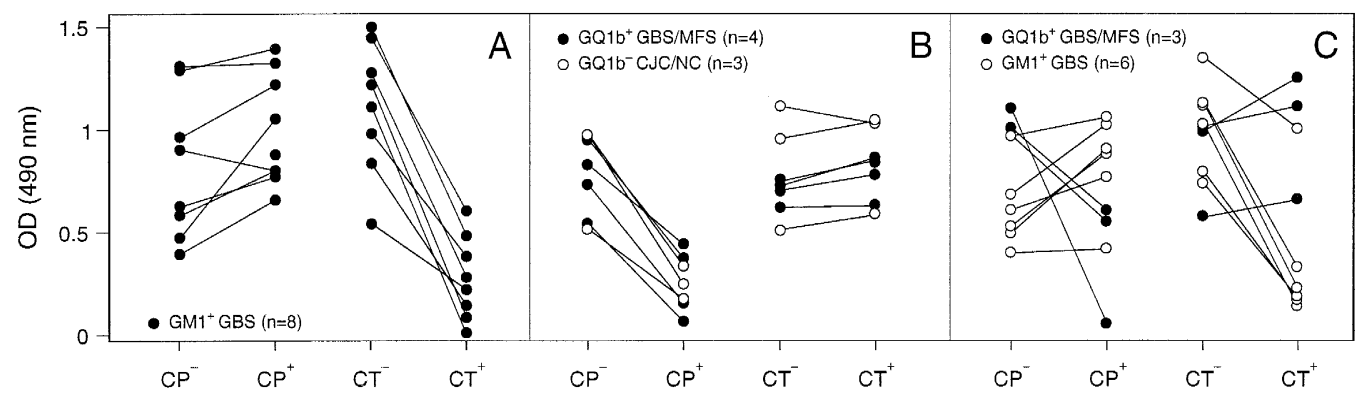

Fig. 3. Serum IgG activity against LPS preincubated with neuraminidase from Clostridium perfringens in $50 \mathrm{mM}$ sodiumacetate buffer $(\mathrm{CP}+)$, $50 \mathrm{mM}$ sodiumacetate buffer only $(\mathrm{CP}-)$, cholera toxin in PBS-1\% BSA $(\mathrm{CT}+)$, or PBS-1\% BSA only $(\mathrm{CT}-)$. These experiments were performed with LPS of $C$. jejuni from GBS patient E (A), MFS patient B (B), and MFS patient A (C). Serum was tested from all patients with antibodies against these LPS.

pneumococcal polysaccharides were present in all patients and controls (data not shown).

\subsection{Specificity of IgG antibodies against LPS}

To further characterize the specificity of the anti-LPS antibodies, we incubated the LPS with sialidases and CT. Binding of $\operatorname{IgG}$ to $C$. jejuni isolate $\mathrm{E}$ in serum from anti-GM1 positive patients was reduced to baseline after blocking the LPS with CT (Fig. 3A). Treatment of the LPS with sialidase $\mathrm{CP}$ had no or an increasing effect on the antibody binding (Fig. 3A). The same results were found with LPS from $C$. jejuni isolates D, F and 3 (data not shown).

Treatment of LPS from $C$. jejuni isolate B with sialidase $\mathrm{CP}$ reduced the binding of $\mathrm{IgG}$ to LPS in serum from the anti-GQ1b positive patients, CJC and NC (Fig. 3B). The reactivity was not influenced by blocking the LPS with CT. The same results were found with LPS from $C$. jejuni isolate C (data not shown). In LPS from $C$. jejuni isolate A a combination of effects was found (Fig. 3C). After blocking with CT the IgG binding to LPS was reduced in anti-GM1 positive patients, but not in anti-GQ1b positive patients. After treatment with sialidase $\mathrm{CP}$, the IgG binding was reduced in anti-GQ1b positive patients but not in anti-GM1 positive patients. Sialidases from CP and $\mathrm{AU}$ gave similar results in all experiments.

\section{Discussion}

The present study demonstrates that the $\mathrm{IgG}$ responses against $C$. jejuni LPS and gangliosides are closely associated in patients with GBS and MFS. Firstly, high IgG activity against LPS from GBS related $C$. jejuni isolates was found in anti-GM1 positive GBS patients. Anti-GQ1b positive GBS and MFS patients had high titers of $\operatorname{IgG}$ against LPS from the MFS related strains. Secondly, the titer course and subclass of the IgG antibodies against LPS corresponded with those of the antibodies against GM1 and GQ1b. Such a similarity in subclass distribution was also found by others (Yuki et al., 1995). Thirdly, the antibody binding with LPS in sera with anti-GM1 or anti-GQ1b antibodies was reduced to baseline after CT and sialidase treatment of the LPS, respectively. These findings suggest that most of the anti-LPS IgG activity in GBS and MFS patients is due to antibodies against ganglioside-like epitopes in LPS, indicating that these epitopes are immunodominant in a humoral immune response against LPS. This further supports the hypothesis that antecedent $C$. jejuni infections in GBS and MFS trigger the production of cross-reactive antibodies against gangliosides.

Molecular mimicry between gangliosides and LPS has been demonstrated with $C$. jejuni isolates from GBS and MFS patients (Yuki et al., 1993; Salloway et al., 1996). Previously we found that anti-GQ1b antibodies cross-react with LPS of $C$. jejuni from MFS patient A, B and C, and anti-GM1 antibodies with $C$. jejuni from GBS patient E and control 3 (Jacobs et al., 1997). In the present study we demonstrate that anti-LPS antibodies in C. jejuni infected GBS patients without anti-ganglioside antibodies are rare. This indicates that, except for these ganglioside-like epitopes, other LPS structures do not induce cross-reactive antibodies. However, $C$. jejuni infection in these patients may induce cross-reactive antibodies against bacterial structures other than LPS. This is supported by the finding that antibodies against peripheral nerve proteins are induced by immunization with $C$. jejuni proteins in animals (Fujimoto and Amako, 1990; Kaldor et al., 1992).

In some patients with anti-ganglioside antibodies we did not find high $\operatorname{IgG}$ activity against LPS. This may result from relatively low titers or different fine-specificities of the anti-ganglioside antibodies in these patients. In previous studies we found no binding of anti-GM1 antibodies with LPS of $C$. jejuni from MFS patient A and GBS patient D (Jacobs et al., 1997). In the present study we demonstrated antibodies against these isolates in a subgroup of the anti-GM1 positive patients. These patients all had additional antibody activity against GD1b, suggesting that the antibodies recognize the shared $\operatorname{Gal}(\beta 1-$ 3)GalNAc-moiety on GM1 and GD1b. The antibodies may also react with this moiety in LPS, since the antibody binding was insensitive to sialidases and could be blocked by $\mathrm{CT}$. This is in accordance with the finding that $\mathrm{CT}$ also 
binds with $\mathrm{Gal}(\beta 1-3)$ GalNAc-containing glycolipids other than GM1 (Schwerer et al., 1995).

In the present study we found antibodies against LPS from MFS associated $C$. jejuni in serum from enteritis and normal controls too. These antibodies are probably directed against ganglioside-like epitopes as well, since sialidase treatment of the LPS reduced the antibody binding. Accordingly, ganglioside-like structures were also demonstrated in C. jejuni from patients without neurological involvement (Aspinall et al., 1993). Our study suggests that these structures may also be immunodominant in uncomplicated $C$. jejuni infections. However, these epitopes induce antibodies with other specificities than in GBS and MFS patients, as indicated by the lack of activity against GM1 and GQ1b in controls.

The anti-LPS antibodies further differ with respect to their subclasses in GBS and MFS patients compared to controls. We found high titers of anti-LPS IgG antibodies in serum from some enteritis patients and normal controls, which were predominantly IgG2. The presence of $\mathrm{IgG} 1$ and IgG3 antibodies against LPS in GBS and MFS patients, suggests that in these patients humoral immune responses against polysaccharides differ from others. The presence of IgG2 antibodies against pneumococcal capsular polysaccharides in all GBS and MFS patients excludes an IgG2 subclass deficiency, and may indicate that the IgG1 and $\mathrm{IgG} 3$ response are restricted to LPS from specific $C$. jejuni strains.

Long-lasting, high titers of IgG1 and IgG3 antibodies are characteristic for $\mathrm{T}$ cell dependent immune responses (Papadea and Check, 1989). The role of T cells in the in vivo production of antibodies against LPS and gangliosides in humans, has not yet been elucidated. In vitro studies indicate that the production of antibodies against both bacterial polysaccharides and gangliosides are stimulated in the presence of activated T cells (Ambrosino et al., 1990; Heidenreich et al., 1994). In the immune response against LPS, $C$. jejuni may induce T cell activation by the production of a protein that binds to LPS, serving as a carrier protein for $\mathrm{T}$ cell help (Willison and Kennedy, 1993). A candidate for this protein may be enterotoxins, which specifically bind with gangliosides and are produced by specific C. jejuni strains (Klipstein and Engert, 1984; Suzuki et al., 1994). If one $C$. jejuni strain expresses both this enterotoxin and ganglioside-like LPS, the enterotoxin may bind to LPS, providing an epitope for T cells. These activated $\mathrm{T}$ cells may skew B cells against LPS to switch to $\mathrm{IgG} 1$ and $\mathrm{IgG} 3$ production.

This subclass switch may be crucial for the pathogenicity of anti-ganglioside antibodies in GBS and MFS. $\mathrm{IgG} 1$ and $\mathrm{IgG} 3$ antibodies are more effective than $\mathrm{IgG} 2$ in activating the classical complement pathway (Feinstein et al., 1986). Interestingly, the suppression of sodium current in sciatic nerve by rabbit anti-GM1 antibodies was found to be complement-dependent (Takigawa et al., 1995). In addition, IgG1 and $\mathrm{IgG} 3$ have a higher affinity for $\mathrm{Fc}$ receptors which play a role in opsonization and phagocytosis (Van de Winkel and Capel, 1993).

In conclusion, our study gives further support to the hypothesis that infections with specific $C$. jejuni strains induce cross-reactive $\operatorname{IgG} 1$ and $\operatorname{IgG} 3$ antibodies against LPS and gangliosides in GBS and MFS patients. Further research is necessary to elucidate the mechanism by which C. jejuni determines the specificity and isotypes of the anti-ganglioside antibodies.

\section{References}

Ambrosino, D.M., Delaney, N.R., Shamberger, R.C., 1990. Human polysaccharide-specific $B$ cells are responsive to pokeweed mitogen and IL-6. J. Immunol. 144, 1221-1226.

Asbury, A.K., Cornblath, D.R., 1990. Assessment of current diagnostic criteria for Guillain-Barré syndrome. Ann. Neurol. 27 (suppl), S21S24.

Aspinall, G.O., McDonald, A.G., Raju, T.S., Pang, H., Moran, A.P., Penner, J.L., 1993. Chemical structures of the core regions of Campylobacter jejuni serotypes O:1, O:4, O:23, and O:36 lipopolysaccharides. Eur. J. Biochem. 213, 1017-1027.

Chiba, A., Kusunoki, S., Obata, H., Machinami, R., Kanazawa, I., 1993. Serum anti-GQ1b IgG antibody is associated with ophthalmoplegia in Miller Fisher syndrome and Guillain-Barré syndrome: Clinical and immunohistochemical studies. Neurology 43, 1911-1917.

Feinstein, A., Richardson, N., Taussig, M.J., 1986. Immunoglobulin flexibility in complement activation. Immunol. Today 7, 169-174.

Fujimoto, S., Amako, K., 1990. Guillain-Barré syndrome and Campylobacter jejuni infection. Lancet 35, 1350.

Hammerström, L., Smith, C.I.E., 1986. IgG subclasses in bacterial infections. Monogr. Allerg. 19, 122-133.

Heidenreich, F., Leifeld, L., Jovin, T., 1994. T cell-dependent activity of ganglioside GM1 - specific B cells in Guillain-Barré syndrome and multifocal motor neuropathy in vitro. J. Neuroimmunol. 49, 97-108.

Jacobs, B.C., Endtz, H.Ph., Van der Meché, F.G.A., Hazenberg, M.P., Achtereekte, H.A.M., Van Doorn, P.A., 1995. Serum anti-GQ1b IgG antibodies recognize surface epitopes on Campylobacter jejuni from patients with Miller Fisher syndrome. Ann. Neurol. 37, 260-264.

Jacobs, B.C., Van Doorn, P.A., Schmitz, P.I.M., Tio-Gillen, A.P., Herbrink, P., Visser, L.H., Hooijkaas, H., Van der Meché, F.G.A., 1996. Campylobacter jejuni infections and anti-GM1 antibodies in Guillain-Barré syndrome. Ann. Neurol. 40, 181-187.

Jacobs, B.C., Hazenberg, M.P., Van Doorn, P.A., Endtz, H.Ph., Van der Meché, F.G.A., 1997. Cross-reactive antibodies against gangliosides and Campylobacter jejuni lipopolysaccharides in patients with Guillain-Barré or Miller Fisher syndrome. J. Infect. Dis. 175, 729-733.

Kaldor, J., Tong, M.Q., Dwyer, B., Huang, Z.H., Johnston, N., Talman, P., Horne, M., 1992. Guillain-Barré syndrome and Campylobacter jejuni / coli. Pathology 24, 125-126.

Klipstein, F.A., Engert, R.F., 1984. Properties of crude Campylobacter jejuni heat-labile enterotoxin. Infect. Immun. 45, 314-319.

Ogawa-Goto, K., Funamoto, N., Ohta, Y., Abe, T., Nagashima, K., 1992. Myelin gangliosides of human peripheral nervous system: An enrichment of GM1 in the motor nerve myelin isolated from Cauda equina. J. Neurochem. 59, 1844-1849.

Ogino, M., Nobile-Orazio, E., Latov, N., 1995. IgG anti-GM1 antibodies from patients with acute motor neuropathy are predominantly of the IgG1 and IgG3 subclasses. J. Neuroimmunol. 58, 77-80.

Oomes, P.G., Jacobs, B.C., Hazenberg, M.P.H., Bänffer, J.R.J., Van der Meché, F.G.A., 1995. Anti-GM1 IgG antibodies and Campylobacter bacteria in Guillain-Barré syndrome: Evidence of molecular mimicry. Ann. Neurol. 38, 170-175. 
Papadea, C., Check, I.J., 1989. Human immunoglobulin G and immunoglobulin G subclasses: Biochemical, genetic, and clinical aspects. Crit. Rev. Clin. Lab. Sci. 27, 27-58.

Rees, J.H., Soudain, S.E., Gregson, N.A., Hughes, R.A.C., 1995a. Campylobacter jejuni infection in Guillain-Barré syndrome. N. Engl. J. Med. 333, 1374-1379.

Rees, J.H., Gregson, N.A., Hughes, R.A.C., 1995b. Anti-ganglioside GM1 antibodies in Guillain-Barré syndrome and their relationship to Campylobacter jejuni infection. Ann. Neurol. 38, 809-816.

Salloway, S., Mermel, L.A., Seamans, M., Aspinall, G.O., Nam Shin, J.E., Kurjanczyk, L.A., Penner, J.L., 1996. Miller Fisher syndrome associated with Campylobacter jejuni bearing lipopolysaccharide molecules that mimic human ganglioside GD3. Infect. Immun. 64, 2945-2949.

Schwerer, B., Neisser, A., Polt, R.J., Bernheimer, H., Moran, A.P., 1995. Antibody cross-reactivities between gangliosides and lipopolysaccharides of Campylobacter jejuni sero-types associated with GuillainBarré syndrome. J. Endotox. Res. 2, 395-403.

Suzuki, S., Kawaguchi, M., Mizuno, K., Takama, K., Yuki, N., 1994 Immunological properties and ganglioside recognition by Campylobacter jejuni-enterotoxin and cholera toxin. FEMS Immunol. Med. Microbiol. 8, 207-212.

Takigawa, T., Yasuda, H., Kikkawa, R., Shigeta, Y., Saida, T., Kitasato, H., 1995. Antibodies against GM1 ganglioside affect $\mathrm{K}^{+}$and $\mathrm{Na}^{+}$ currents in isolated rat myelinated nerve fibers. Ann. Neurol. 37, 436-442.

Van der Meché, F.G.A., Van Doorn, P.A., 1995. Guillain-Barré syndrome and chronic inflammatory demyelinating polyneuropathy: Im- mune mechanisms and update on current therapies. Ann. Neurol. 37 (suppl.), S14-S31.

Van de Winkel, J.G.J., Capel, P.J.A., 1993. Human IgG Fc receptor heterogeneity: Molecular aspects and clinical implications. Immunol. Today 14, 215-221.

Walsh, F.S., Cronin, M., Koblar, S., Doherty, P., Winer, J., Leon, A., Hughes, R.A.C., 1991. Association between glycoconjugate antibodies and Campylobacter infection in patients with Guillain-Barré syndrome. J. Neuroimmunol. 34, 43-51.

Westphal, O., Jann, K., 1965. Bacterial lipopolysaccharides, extraction with phenol-water and further applications of the procedure. Methods Carbohydr. Chem. 5, 83-91.

Willison, H.J., Kennedy, P.G.E., 1993. Gangliosides and bacterial toxins in Guillain-Barré syndrome. J. Neuroimmunol. 46, 105-112.

Willison, H.J., Veitch, J., 1994. Immunoglobulin subclass distribution and binding characteristics of anti-GQ1b antibodies in Miller Fisher syndrome. J. Neuroimmunol. 50, 159-165.

Yuki, N., Taki, T., Inagaki, F., Takahashi, M., Saito, K., Handa, S., Miyatake, T., 1993. A bacterium lipopolysaccharide that elicits Guillain-Barré syndrome has a GM1 ganglioside-like structure. J. Exp. Med. 178, 1771-1775.

Yuki, N., Taki, T., Takahashi, M., Saito, K., Yoshino, H., Tai, T., Handa, S., Miyatake, T., 1994. Molecular mimicry between GQ1b ganglioside and lipopolysaccharides of Campylobacter jejuni isolated from patients with Fisher's syndrome. Ann. Neurol. 36, 791-793.

Yuki, N., Ichihashi, Y., Taki, T., 1995. Subclass of IgG antibody to GM1 epitope-bearing lipo- polysaccharide of Campylobacter jejuni in patients with Guillain-Barré syndrome. J. Neuroimmunol. 60, 161-164. 